\title{
Diagnostic relevance of urinary steroid profiles on ovarian granulosa cell tumors: two case reports
}

\author{
Anita Bufa ${ }^{1 *}$, Nelli Farkas ${ }^{1}$, Zsolt Preisz ${ }^{1}$, Viktória Poór ${ }^{1}$, Csilla Páger ${ }^{1}$, Sándor Szukits², Bálint Farkas 3,4 \\ and Péter Miklós Gőcze ${ }^{3}$
}

\begin{abstract}
Background: Granulosa cell tumor of the ovary is the most frequent sex cord stromal tumor and represents 2 to $5 \%$ of all primary ovarian cancers. Ovarian granulosa cell tumor is a malignant tumor with slow progression and in some cases this tumor is hormonally active. The recurrence of granulosa cell tumor often happens after 5 years.

Case presentation: We describe two cases of postmenopausal women with adult-type granulosa cell tumors of the ovary. Patient 1 is a 49-year-old European woman with a recurrent tumor; patient 2 is a 55-year-old European woman without recurrence of tumor. Urinary steroid profiles of patient 1 were monitored during a 5-year period starting from before an operation (13 samples). In patient 2, the urinary steroid profiles were monitored during a 3year period starting from after an operation (six samples). The 24-hour urinary samples were examined and the urinary concentration of 20 androgen, progesterone, and corticoid metabolites was quantitatively determined by gas chromatography-mass spectrometry with selected ion-monitoring mode.

Conclusions: Based on these cases a correlation could be observed between increased levels of the urinary steroids and the recurrence of ovarian granulosa cell tumor; therefore, we concluded that a urinary steroid profile could be a more effective method to follow-up such patients compared to the traditional serum hormones determinations supplemented with conventional tumor markers.
\end{abstract}

Keywords: Ovarian granulosa cell tumor, Urinary steroid profiles, Diagnostics, Gas chromatography-mass spectrometry

\section{Background}

Granulosa cell tumor (GCT) of the ovary is a malignant tumor originating from the sex-cord stromal cells of the ovary and represents approximately $5 \%$ of all primary ovarian cancers [1-3]. Approximately $4 \%$ occur before puberty (juvenile GCT) and the majority of the cases are the adult type of GCT (occur in people of reproductive age and postmenopausal age) [4]. In some cases these tumors are hormonally active, they often express steroid hormone receptors $[3,5]$. The natural history of GCT is generally long with slow progression, and recurrence often happens after 5 years of follow-up [6]. We report

\footnotetext{
* Correspondence: anita.bufa@aok.pte.hu

${ }^{1}$ Institute of Bioanalysis, Faculty of Medicine, University of Pécs, Szigeti street

12, Pécs 7624, Hungary

Full list of author information is available at the end of the article
}

two cases of adult GCT of the ovary and describe the changes experienced in urinary steroid profiles which could help in following-up the presence, progression, and recurrence of this tumor.

\section{Case presentation \\ Patient 1}

A 49-year-old European, postmenopausal woman who was diagnosed with stage T1a ovarian GCT had recurrence 7 years after primary surgery and five cycles of chemotherapy: epirubicin + cisplatin. On admission, the results of her neurological examination were normal. A physical examination revealed two cystic masses above her vagina on the left and slightly to the right that varied from 6 to $10 \mathrm{~cm}$ in diameter. The results of the rest of her physical examination were normal. She had given 
birth to three children. In January 2011, magnetic resonance imaging (MRI) depicted a large pelvic mass with inhomogeneous signal intensity $(87 \times 108 \times 70 \mathrm{~mm})$, a diffuse peritoneal metastasis $(68 \times 35 \mathrm{~mm})$ with ascites, a parailiacal pathological lymph node $(15 \times 10 \mathrm{~mm})$, and an inguinal pathological lymph node $(62 \times 32 \mathrm{~mm})$ from the left side of her pelvis (Fig. 1). A laboratory examination did not reveal elevated levels of serum tumor markers and hormones: carcinoembryonic antigen (CEA), $1.6 \mathrm{ng} / \mathrm{ml}$; carbohydrate antigen-125 (CA-125), $18.45 \mathrm{U} / \mathrm{ml}$; carbohydrate antigen-15-3 (CA-15-3), $20 \mathrm{U} / \mathrm{ml}$; carbohydrate antigen-19-9 (CA-19-9), $0.6 \mathrm{U} / \mathrm{ml}$; alpha-fetoprotein (AFP), $2.3 \mu \mathrm{g} / \mathrm{l}$; follicle-stimulating hormone (FSH), 23.1 $\mathrm{U} / \mathrm{l}$; luteinizing hormone (LH), $38.9 \mathrm{U} / \mathrm{l}$; progesterone (P), $2 \mathrm{nmol} / \mathrm{l} ; 17 \beta$-estradiol $\left(\mathrm{E}_{2}\right), 64 \mathrm{pmol} / \mathrm{l}$; testosterone (T), $0.92 \mathrm{nmol} / \mathrm{l}$; and androstenediol (A), $7.74 \mathrm{nmol} / \mathrm{l}$. She underwent abdominal hysterectomy with bilateral salpingo-oophorectomy and omentectomy 3 months later. A histologic examination revealed recurrence of GCT. Immunohistochemical staining gave positive results for alpha-inhibin. After the operation (OP), she was given three cycles of chemotherapy: bleomycin, etoposide, and cisplatin (BEP). Two months later she underwent metastasectomy through laparotomy and she was given three cycles of third line chemotherapy: cyclophosphamide and doxorubicin (CAP I). Despite surgeries and chemotherapies, in August 2014 a computed tomography (CT) scan showed significant progression of the recurrent GCT, local tumor recurrence, the presence of diffuse peritoneal carcinosis, ascites, and inguinal pathological lymph node (Fig. 2). A laboratory examination did not reveal elevated levels of serum tumor markers: CEA, $1.3 \mathrm{ng} / \mathrm{ml}$; CA-125, $13 \mathrm{U} / \mathrm{ml}$. Then she was given three cycles of re-induction of epirubicin + cisplatin chemotherapy. Three months later in February 2015, CT demonstrated 25\% regression of the tumor (Fig. 2). Then, she refused further parenteral chemotherapy. From April 2016 she received oral anastrozole (Arimidex ${ }^{\circ}$ ) therapy. During the treatments, before and after the OP, 13 24-hour urinary samples were collected at different time points. Her urine samples were stored at $-20{ }^{\circ} \mathrm{C}$ until analysis. We performed sample pre-treatment, and the extraction method we used is based on Shackleton and Whitney's extraction method [7]. After the sample preparation processes the concentrations $(\mu \mathrm{g} / 24$ hours) of the following urinary androgen, progesterone $(\mathrm{P})$, and corticoid metabolites were determined by gas chromatography-mass spectrometry (GC-MS)/ selected ion-monitoring (SIM): androsterone (An), etiocholanolone $(\mathrm{Et})$, dehydroepiandrosterone (DHEA), 11ß-hydroxyandrosterone (11-OH-An), 16-hydroxy-
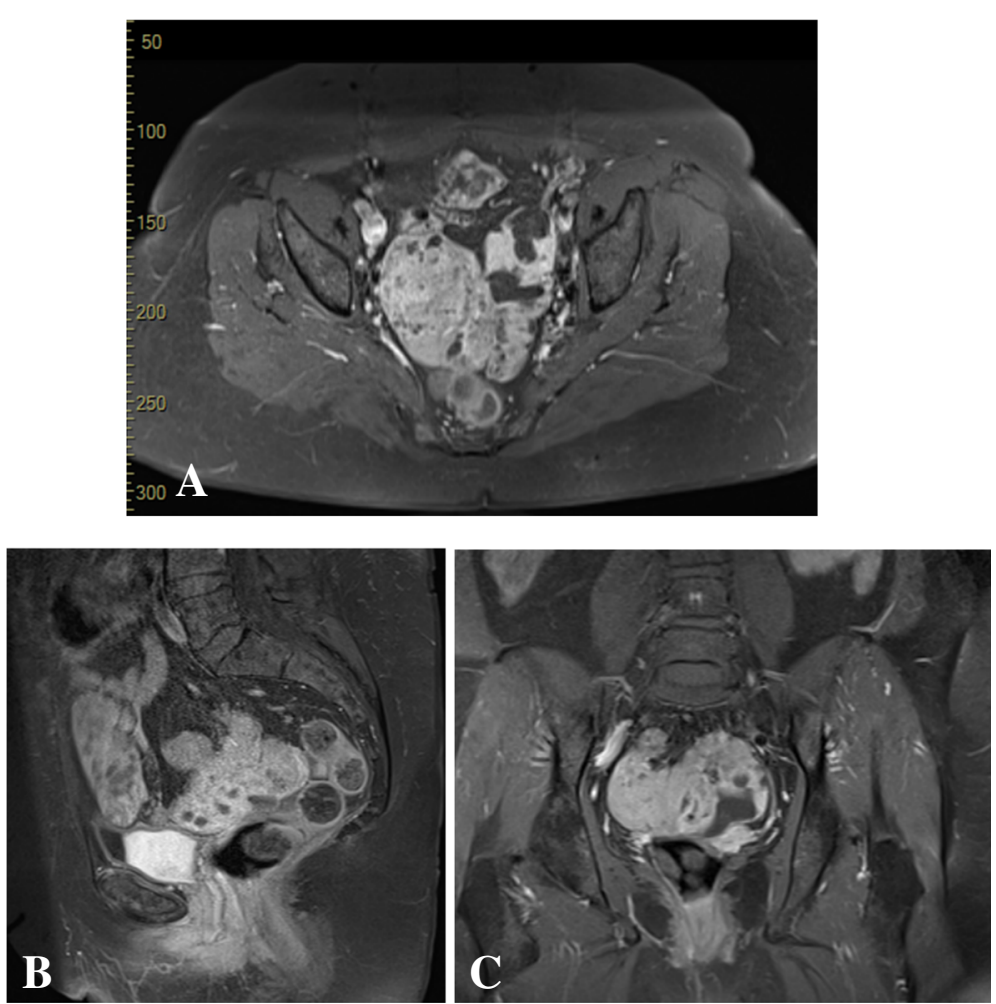

Fig. 1 Patient 1 - magnetic resonance images of the recurrence of ovarian granulosa cell tumor. a Axial, $\mathbf{b}$ sagittal, and c coronal T2-weighted images showing a local tumor recurrence $(87 \times 108 \times 70 \mathrm{~mm})$, diffuse peritoneal metastasis $(68 \times 35 \mathrm{~mm})$ with ascites from the pelvis, a parailiacal pathological lymph node $(15 \times 10 \mathrm{~mm})$, and an inguinal pathological lymph node $(62 \times 32 \mathrm{~mm})$ from the left side of the pelvis 

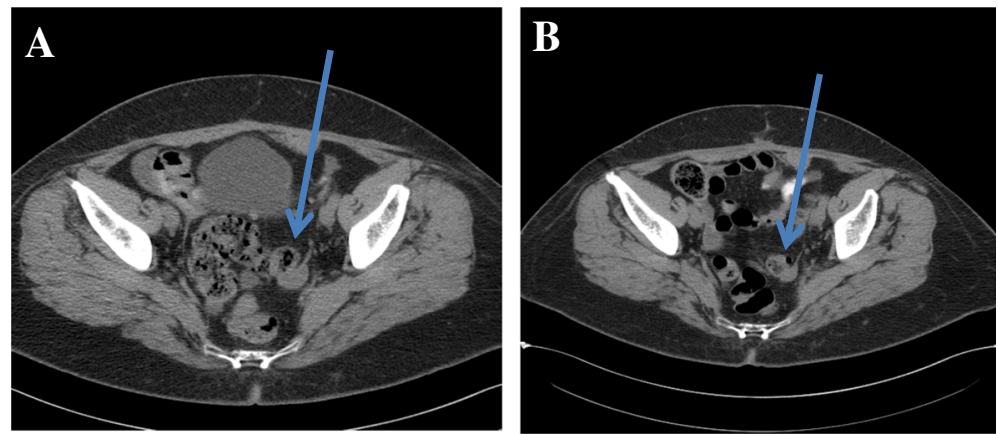

Fig. 2 Patient 1 Computer tomography images of recurrent ovarian granulosa cell tumour. a The progression of tumour (local tumour recurrence (blue arrow), diffuse peritoneal carcinosis with ascites and inguinal pathological lymph node), and $\mathbf{b}$ the regression of local recurrence tumour (blue arrow)
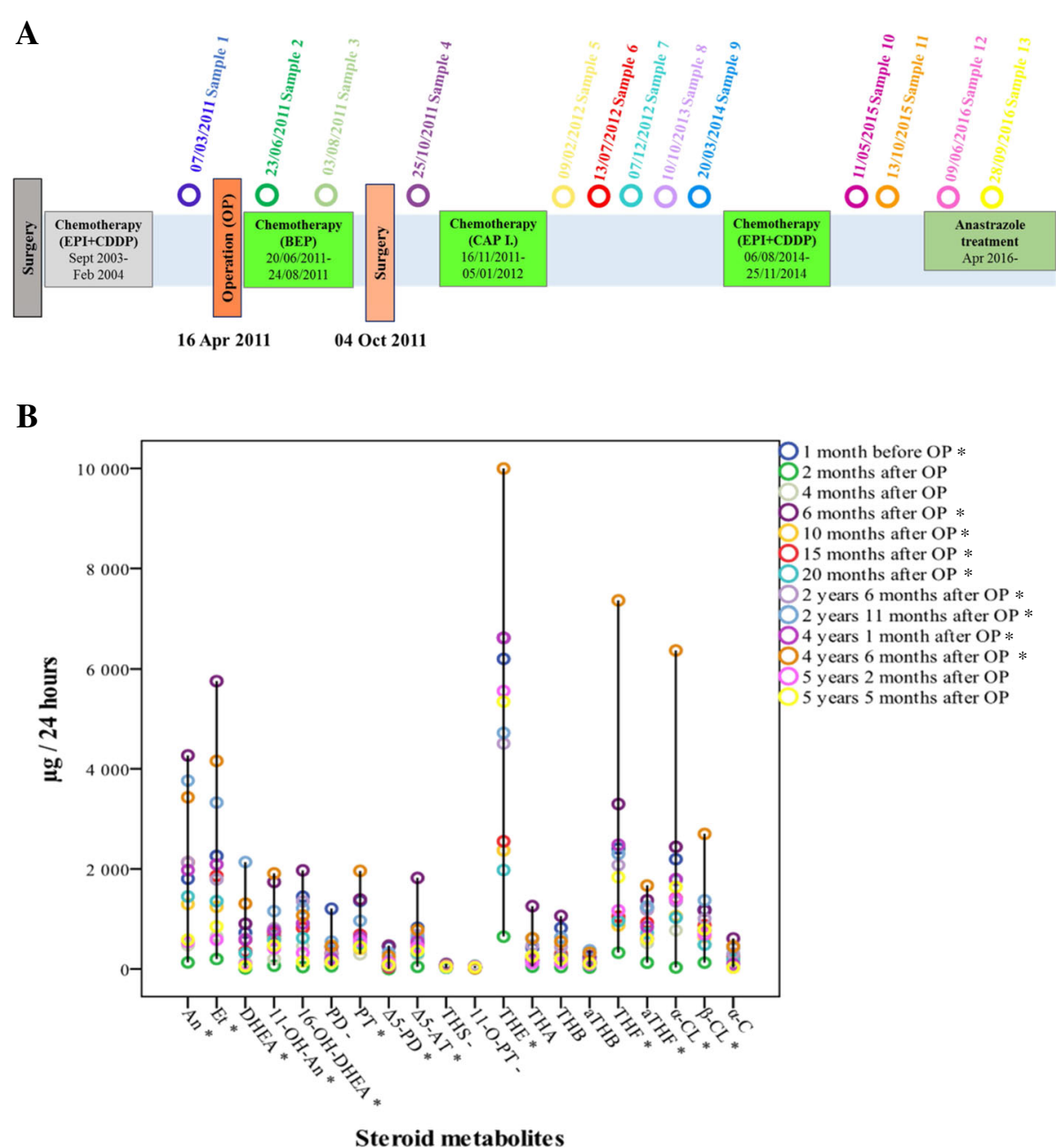

Fig. 3 Patient 1 a The interventions and treatments of patient and the collection of urine samples. $\mathbf{b}$ The levels of the urinary steroid metabolites at different time points. ${ }^{*}$ represents a steroid level that is higher than the same age and same sex reference value. - represents a steroid level that is lower than the reference value in all samples 
DHEA (16-OH-DHEA), pregnanediol (PD), pregnanetriol $(\mathrm{PT})$, pregnenediol $(\Delta 5-\mathrm{PD})$, androstenetriol $(\Delta 5-\mathrm{AT})$, tetrahydro-11-deoxycortisol (THS), 11-keto-pregnanetriol (11-O-PT), tetrahydrocortisone (THE), tetrahydro-11dehydrocorticosterone (THA), tetrahydrocorticosterone (THB), allo-tetrahydrocorticosterone (aTHB), tetrahydrocortisol (THF), allo-tetrahydrocortisol (aTHF), $\alpha$-cortolone $(\alpha-C L), \beta$-cortolone $(\beta-C L)$, and $\alpha$-cortol $(\alpha-$ C). All components were detected in all samples. The interventions and treatments of patient 1 , the collection of urine samples, and the levels of the urinary steroid metabolites are shown in Fig. 3.

\section{Patient 2}

A 55-year-old European, postmenopausal woman was diagnosed with stage T1a ovarian GCT in October 2011. On admission, the results of her neurological examination were normal. Her physical examination was otherwise unremarkable. A CT scan depicted a large, single pelvic mass with inhomogeneous signal intensity $(164 \times 113 \times 146 \mathrm{~mm})$ and ascites. A laboratory examination did not reveal an elevated level of CA-125 (11 U/ml) tumor marker. She underwent laparotomy and the entire tumor was removed. The pathologic diagnosis was GCT. No further treatment was given. On clinical and radiological examination 11 months later, she was found to be free of the disease. After the OP, during the oncological follow-up, six 24-hour urinary samples were collected at different time points. Her urinary concentrations $(\mu \mathrm{g} / 24$ hours) of An, Et, DHEA, 11-OH-An, 16-OH-DHEA, PD, PT, $\triangle 5$-PD, $\Delta 5$-AT, THS, 11-O-PT, THE, THA, THB, aTHB, THF, aTHF, $\alpha-C L, \beta-C L$, and $\alpha-C$ were determined by GC-MS/SIM. All components were
A

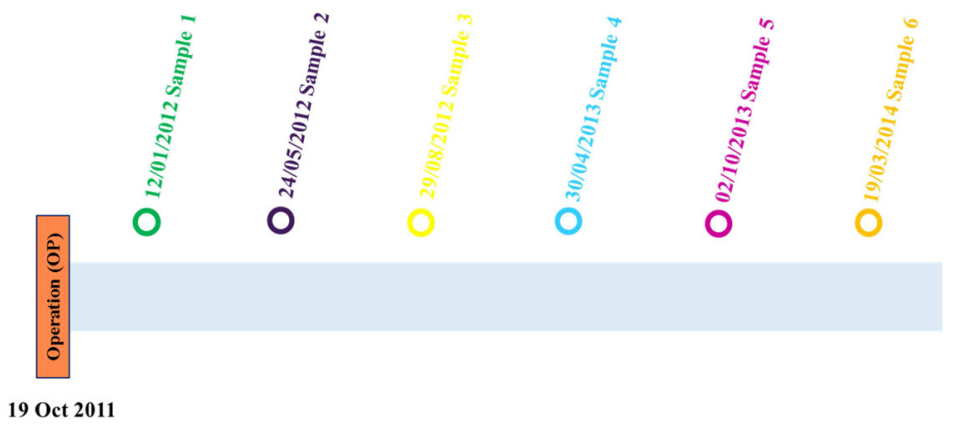

B

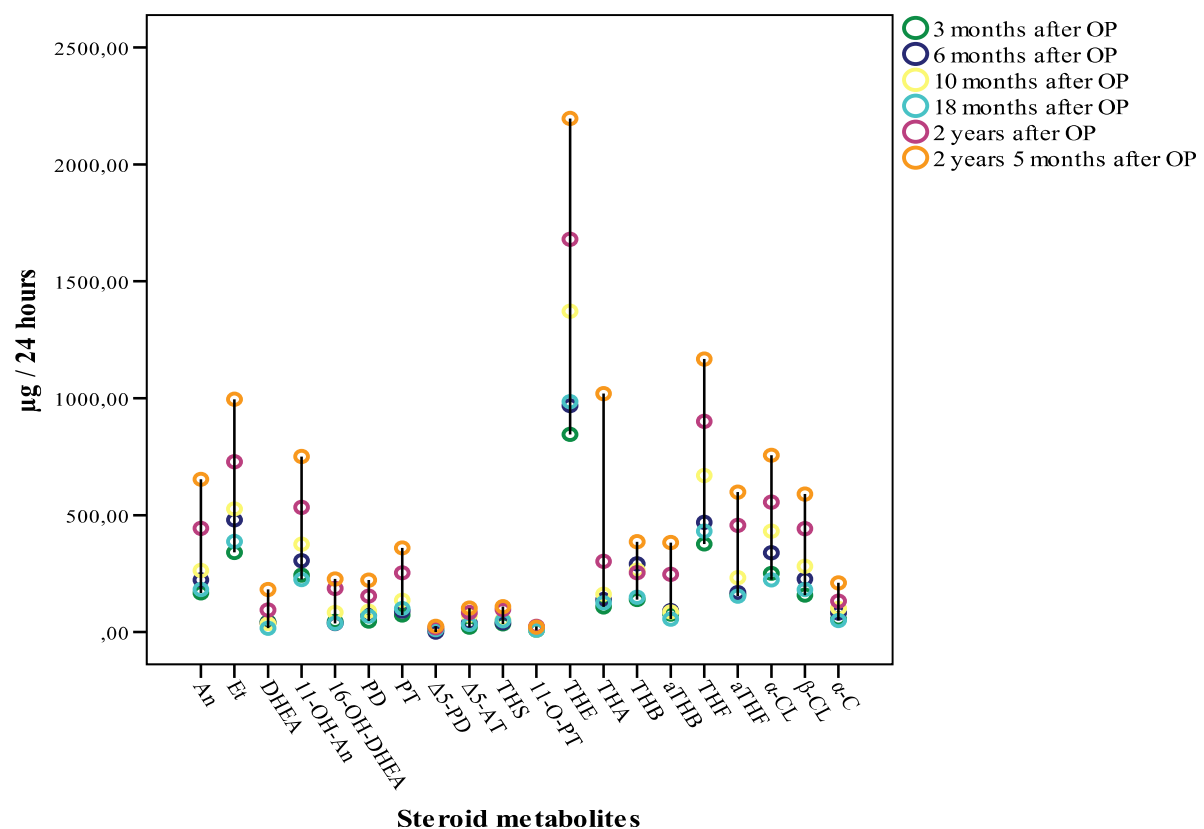

Fig. 4 Patient 2. a The interventions and treatments of the patient and the collection of urine samples. $\mathbf{b}$ The levels of the urinary steroid metabolites at different time points 
detected in all samples. The interventions and treatments of patient 2 , the collection of urine samples, and the levels of the urinary steroid metabolites are shown in Fig. 4.

\section{Discussion}

GCT is hormonally active, so the qualitative and quantitative determination of steroid hormones has an important role in the follow-up and the diagnostics of this tumor. The urinary steroid profile is a feasible method, which allows us to measure several steroid groups in parallel and it is a noninvasive procedure.

In the first case, 1 month before the OP, in the first sample the urinary concentrations of An, Et, 11-OH-An, 16OH-DHEA, $\Delta 5$-AT, PT, $\Delta 5$-PD, THE, aTHF, and $\alpha$-CL were higher than the same age and same sex reference values. A laboratory examination did not reveal elevated levels of serum tumor markers and hormones. At 2 and 4 months after the OP, during the BEP chemotherapy (samples 2 and 3), the urinary levels of all metabolites were lower than the reference values. Six months after the OP (after BEP chemotherapy and metastasectomy, before CAP I chemotherapy) the urinary concentrations of An, Et, 11OH-An, 16-OH-DHEA, $\triangle 5$-AT, PT, $\triangle 5$-PD, THE, THA, THB, THF, aTHF, $\alpha-C L$ and $\alpha-C$ were higher than the reference values (sample 4). After CAP I chemotherapy, a laboratory examination did not reveal elevated levels of serum tumor markers; however, in samples 5 to 8 (10 months, 15 months, 20 months, and 2 years 6 months after $\mathrm{OP})$ the urinary concentrations of An, 11-OH-An, and $\Delta 5$ AT were higher than the reference values. In sample $9(2$ years 11 months after OP and before epirubicin + cisplatin chemotherapy) the urinary concentrations of An, Et, DHEA, 11-OH-An, 16-OH-DHEA, $\Delta 5$-AT, PT, $\Delta 5$-PD, THE, aTHF, and $\alpha-C L$ were found to be higher than the reference values again. In addition, a CT examination revealed that the tumor had progressed considerably. The elevated urinary hormone levels of the previous samples (samples 5 to 8 ) might have already indicated this progress. After epirubicin + cisplatin chemotherapy in sample 10 (4 years 1 month after OP), the urinary concentrations of six metabolites (An, 11-OH-An, $\Delta 5$-AT, PT, THE, and $\alpha-\mathrm{CL}$ ) were higher than the reference values; however, CT showed regression of the tumor. In sample 11 (4 years 6 months after OP and after epirubicin + cisplatin chemotherapy), the urinary concentrations of An, Et, DHEA, 11-OH-An, 16-OH-DHEA, $\Delta 5$-AT, PT, THE, THF, aTHF, $\alpha$-CL, and $\beta$ $\mathrm{CL}$ were found to be higher than the reference values again. Under the anastrozole treatment in samples 12 and 13 (5 years 2 months and 5 years 5 months after OP), only the urinary concentration of THE was higher, the urinary concentrations of other metabolites were lower than the reference values. In all urine samples the concentrations of PD, THS, and 11-O-PT were lower than the reference values.
To summarize, before the OP the concentrations of urinary metabolites of serum androgens, pregnenolone, and 17-hydroxyprogesterone were elevated. The concentrations of the urinary metabolites of P, 21-deoxycortisol, and 11deoxycortisol were low. These changes were found after further treatments (surgery and chemotherapies), so they referred to the presence of the recurrent GCT. The elevated levels of the urinary metabolites of cortisol and cortisone referred to the effects of the stress. The chemotherapy and the aromatase inhibitor (anastrozole) treatments amended the steroid metabolism.

In case 2 the urinary concentrations of the metabolites are presented in Fig. 4. After the OP, during a 3-year follow-up period in all urine samples (samples 1 to 6) the concentrations of 20 steroid metabolites were lower than the reference values.

The obtained urinary steroid concentrations, as patient 2 was free of the GCT after an OP, corresponded to the postmenopausal state of women without ovaries.

\section{Conclusions}

Our results suggest that the recurrence of GCT changes urinary steroid profiles, which was indicated by the differences between the urinary steroid levels of the two patients. To confirm that the presence of a GCT can be identified based on a urinary steroid profile, we plan to carry out further multicenter clinical trials.

\section{Abbreviations \\ 11-OH-An: 11ß-hydroxyandrosterone; 11-O-PT: 11-keto-pregnanetriol; 16-OH- DHEA: 16-hydroxy-DHEA; A: Androstenediol; AFP: Alpha-fetoprotein; \\ An: Androsterone; aTHB: Allo-tetrahydrocorticosterone; aTHF: Allo- tetrahydrocortisol; BEP: Bleomycin, etoposide, and cisplatin; CA- 125: Carbohydrate antigen 125; CA-15-3: Carbohydrate antigen 15-3; CA-19- 9: Carbohydrate antigen 19-9; CAP I: Cyclophosphamide and doxorubicin; CEA: Carcinoembryonic antigen; CT: Computed tomography; \\ DHEA: Dehydroepiandrosterone; $E_{2}: 17 \beta$-estradiol; Et: Etiocholanolone; FSH: Follicle-stimulating hormone; GC-MS: Gas chromatography-mass spec- trometry; GCT: Granulosa cell tumor; LH: Luteinizing hormone; MRI: Magnetic resonance imaging; OP: Operation; P: Progesterone; PD: Pregnanediol; PT: Pregnanetriol; SIM: Selected ion-monitoring; T: Testosterone; THA: Tetrahydro-11-dehydrocorticosterone; THB: Tetrahydrocorticosterone; THE: Tetrahydrocortisone; THF: Tetrahydrocortisol; THS: Tetrahydro-11- deoxycortisol; a-C: a-cortol; a-CL: a-cortolone; $\beta$-CL: $\beta$-cortolone; $\Delta 5$ - AT: Androstenetriol; $\triangle 5-P D$ : Pregnenediol}

\section{Acknowledgements}

We thank the University of Pécs Clinical Centre, Department of Radiology and the Pécs Diagnostic Center for the MR and CT images.

\section{Funding}

The work was supported by application KA-2015-16 of Faculty of Medicine, University of Pécs.

\section{Availability of data and materials}

The data that support the findings of this study are available from the corresponding author upon reasonable request.

\section{Authors' contributions}

AB made substantial contributions to the conception and the design of study, and she is responsible for all corrections made to the manuscript. NF participated in study design and performed the statistical analysis. ZP and VP carried out the measurements of urinary steroid profiles and participated in 
study design. CP participated in study design. SS performed the radiological assessments of the patients and is responsible for the interpretation within the manuscript of the radiological findings. BF participated in study design and coordination. PMG participated in study design, collection of samples, and coordination. All authors read and approved the final manuscript.

\section{Competing interests}

The authors declare that they have no competing interests.

\section{Consent for publication}

Written informed consents were obtained from the patients for publication of this case report and any accompanying images. A copy of the written consents is available for review by the Editor-in-Chief of this journal.

\section{Ethics approval and consent to participate}

The study was approved by the Regional Research Ethics Committee (approval no. 2785/2006 and 2998/2015) and the patients gave informed consent.

\section{Publisher's Note}

Springer Nature remains neutral with regard to jurisdictional claims in published maps and institutional affiliations.

\section{Author details}

'Institute of Bioanalysis, Faculty of Medicine, University of Pécs, Szigeti street 12, Pécs 7624, Hungary. ${ }^{2}$ Department of Radiology, University of Pécs Clinical Centre, Ifjúság street 13 , Pécs 7624 , Hungary. ${ }^{3}$ Department of Obstetrics and Gynaecology, University of Pécs Clinical Centre, Édesanyák street 17, Pécs 7624, Hungary. ${ }^{4}$ MTA-PTE Human Reproduction Scientific Research Group Hungarian Academy of Sciences (MTA), Pécs, Hungary.

Received: 1 December 2016 Accepted: 18 May 2017

Published online: 22 June 2017

\section{References}

1. Fox HAK, Langley FA. A clinicopathologic study of 92 cases of granulosa cell-tumor of the ovary with special reference to the factors influencing prognosis. Cancer. 1975;35:231-41.

2. Pectasides D, Pectasides E, Psyri A. Granulosa cell tumor of the ovary. Cancer Treat Rev. 2008;34:1-12.

3. Schumer ST, Cannistra SA. Granulosa cell tumor of the ovary. J Clin Oncol. 2003;21(6):1180-9.

4. Young RH, Dickersin GR, Scully RE. Juvenile granulosa cell tumor of the ovary. A clinicopathological analysis of 125 cases. Am J Surg Pathol. 1984; 8(8):575-96

5. Colombo N, Parma G, Zanagnolo V, Insinga A. Management of ovarian stromal cell tumors. J Clin Oncol. 2007;25:2944-51.

6. Bjorkholm E, Silfversward C. Prognostic factors in granulosa-cell tumors. Gynecol Oncol. 1981;11(3):261-74.

7. Shackleton $\mathrm{CHL}$, Whitney JO. Use of Sep-pak ${ }^{\circledR}$ cartridges for urinary steroid extraction: evaluation of the method for use prior to gas chromatographic analysis. Clin Chim Acta. 1980;107:231-43.

\section{Submit your next manuscript to BioMed Central and we will help you at every step:}

- We accept pre-submission inquiries

- Our selector tool helps you to find the most relevant journal

- We provide round the clock customer support

- Convenient online submission

- Thorough peer review

- Inclusion in PubMed and all major indexing services

- Maximum visibility for your research

Submit your manuscript at www.biomedcentral.com/submit
Biomed Central 